\title{
Green Technology for Biodiesel Production From Mesua Ferrea L. Seed Oil
}

\author{
Mohammad Aslam ${ }^{1}$, Prashant Saxena ${ }^{2}$ \& Anil K. Sarma ${ }^{1}$ \\ ${ }^{1}$ Sardar Swaran Singh National Institute of Renewable Energy, India \\ ${ }^{2}$ DR BR Ambedkar NIT Jalandhar, India \\ Correspondence: Anil K. Sarma, Sardar Swaran Singh National Institute of Renewable Energy, India. Tel: \\ 91-998-842-5251. E-mail: anil_tu@yahoo.co.in
}

Received: October 4, 2013 Accepted: February 15, 2014 Online Published: April 30, 2014

doi:10.5539/eer.v4n2p11 URL: http://dx.doi.org/10.5539/eer.v4n2p11

\begin{abstract}
In this paper, the non-edible Mesua ferrea L. (MFL) seed oil with an acid value $18.8 \mathrm{mg} \mathrm{KOH} / \mathrm{g}$ of oil, was tranesterified in the presence $1 \mathrm{MPa}$ hydrogen pressure and also without the application of external pressure at 250-275 ${ }^{\circ} \mathrm{C}$ for 1 hour. The heterogeneous 1-5 wt.\% Musa balbisiana Colla underground stem (MBCUS) ash catalyst was used during transesterification. The catalyst has a nano-metric dimension and has a versatile composition that consist of several alkali metal oxides, alkaline earth metal oxides, non-transition metal oxides and nonmetal oxides. The resultant biodiesel was separated using rotary vacuum evaporator and purified using molecular sieve and carbon columns. The biodiesel so obtained from MFL seed oil have been characterized as per available methods and found that the fuel properties are in conformity to ASTM and EN standards. 5 wt.\% catalyst was found more effective as compared to other composition during ethanolysis. The effect of hydrogen pressure upon tranesterification was found negligible. Ethanol is a renewable liquid because it is made from renewable precursor such as biomass. It is expected that the use of whole renewable precursor during the process will fulfil the demand of $100 \%$ Green Technology for biodiesel production.
\end{abstract}

Keywords: biodiesel, tranesterification, ethanolysis, Mesua ferrea L., green technology

\section{Introduction}

Due to the limited resources of fossil fuel, increasing prices of crude oil and environmental concerns over the past couple of decades, biodiesel has recently gained significant attention (Lukic, Krstic, Jovanovic, \& Skala, 2009). Biodiesel refers to a vegetable oil or animal fat-based diesel fuel consisting of alkyl (methyl, propyl, or ethyl) esters obtained by chemical reaction of the lipids (vegetable oil, animal fat) with an alcohol. Chemically, biodiesel consists of alkyl esters instead of the alkanes and aromatic hydrocarbons of petroleum derived diesel (Adebayo, Ameen, \& Abass, 2001). More than 350 oil-bearing crops have been identified, among which mainly jatropha, sunflower, safflower, soybean, cottonseed, rapeseed, and peanut oils are considered to be a potential alternative fuels for diesel engines. Nonetheless, other unknown oleaginous crops, which are being grown in less-favoured countries, could perform well as an adequate fuel with chemical and physical properties similar to those of diesel fuels (Dorado, Ballesteros, Lopez, \& Mittelbach, 2004). As India is deficient in edible oils, non-edible oils become the primary choice for biodiesel. Generally, a blend of $5 \%$ to $20 \%$ is proposed in India (Dwivedi, Jain, \& Sharma, 2011).

Mesua ferrea L. (MFL) is a timber plant that grows naturally in the northeastern parts of the Himalayan regions of India and in Srilanka. The oil seed contains 55-57 wt.\% nonedible, reddish-brown-colored oil (the shelled kernel contains $>75$ wt.\% oil), which had been traditionally used as fuels (Sarma \& Konwer, 2005). It is used in folk medicine for the treatment of fever, dyspepsis and renal diseases (Dennis, Kumar, \& Srimannarayana, 1988) Biodiesel (i.e., the fatty acid alkyl ester) can be processed through the conventional tranesterification process. However the most commonly used methanolysis cannot be regarded as a green technology because methanol is mostly derived from the fossil fuel sources. Under such conditions, vegetable oils can be ethanolysed under high pressure, temperature conditions using some renewable catalyst (Zhou, Konar, \& Boocock, 2003). 


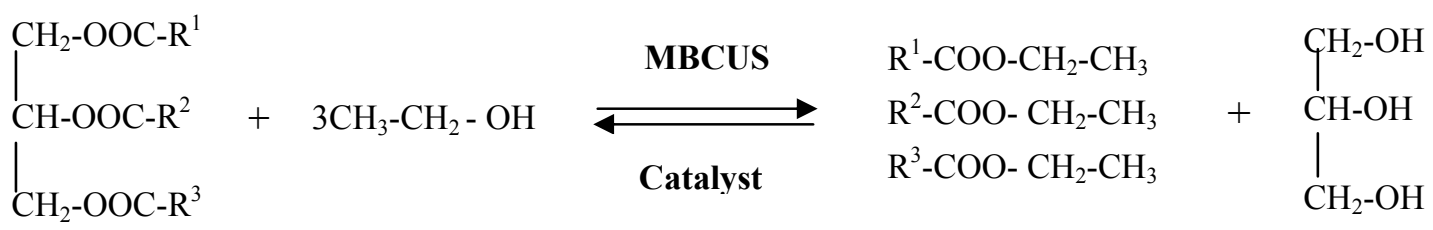

Figure 1. General tranesterification reaction of MFL to FAEE with MBCUS nano-catalyst

The commonly used homogeneous base catalysts are $\mathrm{NaOH}, \mathrm{KOH}$ and their alkoxides. Homogeneous alkali-catalyzed transesterification is much faster than acid-catalyzed transesterification (Vicente, Martınez, \& Aracil, 2005). However, a large amount of water is needed to transfer the catalysts from the organic phase to a water phase after the reaction. So, it is considerably more costly to separate the catalyst from the produced solution (Ebiura, Echizen, Ishikawa, Murai, \& Baba, 2005; Kim et al., 2004; Dorado, Ballesteros, Lopez, \& Mittelbach, 2004).

Heterogeneous base catalysts have many advantages: they are noncorrosive, environmentally benign and present fewer disposal problems. Meanwhile, they are much more easily separated from the liquid products and can be designed to give higher activity, selectivity and longer catalyst lifetimes (Gryglewicz, 1999; Tanabe \& Holderich, 1999).

Musa balbisiana Colla underground stem (MBCUS) derived ash has been employed as a heterogeneous catalyst in this work for the first time for ethanolysis of MFL seed oil, which was also covered recently for methanolysis of Jatropha oil having high percentage of free fatty acids (Sarma, Kumar, Aslam, \& Chouhan, 2014).

Thus a single step transesterification process with ethanol in a high pressure- high temperature (HPHT) batch process under various temperature ranges has been refined and discussed in this study. Moreover, the product obtained has been analysed for different fuel properties as envisaged for biodiesel as per ASTM standards. The details of the catalyst characterization and use during transesterification of Mesua Ferrea L oil having high percentage of free fatty acids have been expounded in the articles.

\section{Experimental}

\subsection{Materials}

Mesua ferrea Linn. (A national tree of Sri Lanka) seeds was procured from the Assam (India) and the seeds were transported to the Institute for physico-chemical analysis and further studies.

MBCUS was employed as catalysts. Petroleum ether $-60-80{ }^{\circ} \mathrm{C}$ AR (Loba Chemie),Chloroform (Merck, 99.8\%), Ethanol (Merck, 99.9\%), Methanol extra pure (Loba Chemie, 99.5\%), Iodine mono chloride/Wijs Solution (Merck), Phenolphthalein (Himedia, 98\%), Potassium hydroxide pellets GR (Merck, 85\% minimum), Sodium thio sulphate penta hydrate GR (Merck, 100\%), Potassium iodide AR (Himedia, 99.8\%), Sodium sulphate anhydrous AR (Himedia, 99\%), Starch soluble AR (Himedia, 99\%), Hexane GC grade (Sigma Aldrich), Heptane GC grade (Sigma Aldrich, 99.5\%), Methanol GC grade (Sigma Aldrich), Methyl heptadecanoate GC grade (Merck), Molecular sieve etc. were used as AR grade chemicals in this study.

\subsection{Feedstock Characterization}

Mesua ferrea L. (MFL) seed kernels were ground, using a mechanical grinder, and extracted in a soxhlet apparatus, using petroleum ether (boiling point $60-80{ }^{\circ} \mathrm{C}$ ). The extracted lipid was obtained by filtering the solvent-lipid mixture to get rid of the solid from solvent before the petroleum ether was removed using rotary evaporator $45-50{ }^{\circ} \mathrm{C}$ and $2.25 \times 10^{3} \mathrm{~Pa}$. The extracted seed oil was stored in freezer at $-2{ }^{\circ} \mathrm{C}$ for subsequent physicochemical analysis. The fatty acid profile of the oil was determined from GC analysis at PBTI, Mohali, India; an NABL accredited laboratory as shown in Table 1. The morphology of MFL seed oil was represented in the Figure 2. 
Table 1. Fatty acid profile of Mesua ferrea L. seed oil

\begin{tabular}{|c|c|c|c|c|c|}
\hline \multicolumn{6}{|c|}{ Saturated Fatty Acids } \\
\hline $\begin{array}{l}\text { S. } \\
\text { No. }\end{array}$ & $\begin{array}{l}\text { Common Name of } \\
\text { Fatty Acids }\end{array}$ & IUPAC/Systematic Name & $\begin{array}{l}\text { Lipid No. } \\
\text { (C:D) }\end{array}$ & $\begin{array}{l}\text { Molecular } \\
\text { Formula }\end{array}$ & $\begin{array}{l}\text { Fatty } \\
\text { Acid (\%) }\end{array}$ \\
\hline 1 & Caproic Acid & Hexanoic acid & $6: 0$ & $\mathrm{C}_{6} \mathrm{H}_{12} \mathrm{O}_{2}$ & 0.022 \\
\hline 2 & Myristic Acid & Tetradecanoic acid & $14: 0$ & $\mathrm{C}_{14} \mathrm{H}_{28} \mathrm{O}_{2}$ & 0.047 \\
\hline 3 & Palmitic Acid & Hexadecanoic acid & $16: 0$ & $\mathrm{C}_{16} \mathrm{H}_{32} \mathrm{O}_{2}$ & 13.635 \\
\hline 4 & Heptadecanoic Acid & Heptadecanoic acid & $17: 0$ & $\mathrm{C}_{17} \mathrm{H}_{34} \mathrm{O}_{2}$ & 0.046 \\
\hline 5 & Stearic Acid & Octadecanoic acid & 18:0 & $\mathrm{C}_{18} \mathrm{H}_{36} \mathrm{O}_{2}$ & 13.646 \\
\hline 6 & Arachidic Acid & Icosanoic acid & $20: 0$ & $\mathrm{C}_{20} \mathrm{H}_{40} \mathrm{O}_{2}$ & 1.3 \\
\hline 7 & Behenic Acid & Docosanoic acid & $22: 0$ & $\mathrm{C}_{22} \mathrm{H}_{44} \mathrm{O}_{2}$ & 0.351 \\
\hline 8 & Lignoceric Acid & Tetracosanoic acid & $24: 0$ & $\mathrm{C}_{24} \mathrm{H}_{48} \mathrm{O}_{2}$ & 0.186 \\
\hline \multicolumn{6}{|c|}{ Mono Unsaturated Fatty Acids } \\
\hline 9 & Palmetoleic Acid & Hexadec-9-enoic acid & $16: 1$ & $\mathrm{C}_{16} \mathrm{H}_{30} \mathrm{O}_{2}$ & 0.087 \\
\hline 10 & Oleic Acid & (9Z)-Octadec-9-enoic acid & $18: 1$ & $\mathrm{C}_{18} \mathrm{H}_{34} \mathrm{O}_{2}$ & 50.713 \\
\hline 11 & Cis-11-Eicosenoic Acid & (Z)-Eicos-11-enoic acid & $20: 1$ & $\mathrm{C}_{20} \mathrm{H}_{38} \mathrm{O}_{2}$ & 0.18 \\
\hline \multicolumn{6}{|c|}{ Poly Unsaturated Fatty Acids } \\
\hline 12 & Linoleic Acid & $\begin{array}{l}(9 Z, 12 Z)-9,12-\text { Octadecadienoic } \\
\text { acid }\end{array}$ & $18: 2$ & $\mathrm{C}_{18} \mathrm{H}_{32} \mathrm{O}_{2}$ & 19.47 \\
\hline 13 & Linolenic Acid & $\begin{array}{l}\text { all-cis-6,9,12-octadecatrienoic } \\
\text { acid }\end{array}$ & $18: 3$ & $\mathrm{C}_{18} \mathrm{H}_{30} \mathrm{O}_{2}$ & 0.316 \\
\hline \multicolumn{6}{|c|}{ Summarized Fatty Acids Analysis } \\
\hline \multicolumn{2}{|c|}{ Total Saturated Fatty Acids (\%) } & 29.233 & & & \\
\hline \multicolumn{2}{|c|}{ Total Unsaturated Fatty Acids (\%) } & 70.766 & & & \\
\hline \multicolumn{2}{|c|}{ Grand Total } & 99.999 & & & \\
\hline
\end{tabular}

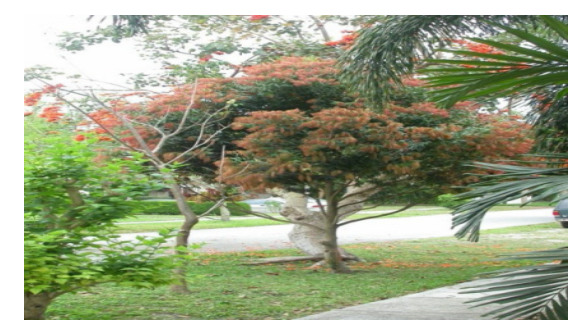

MFL Tree (National Tree of Sri Lanka)

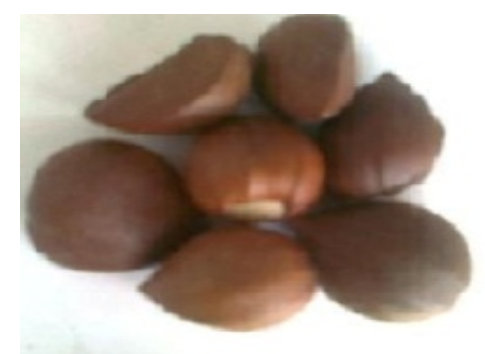

MFL Seeds

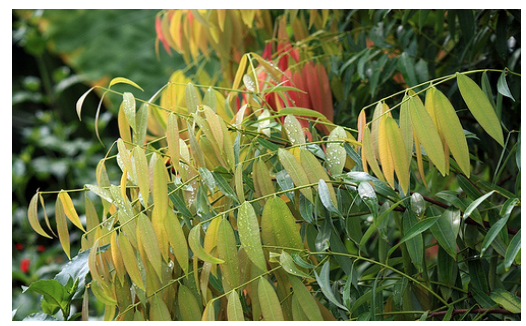

MFL Leaves

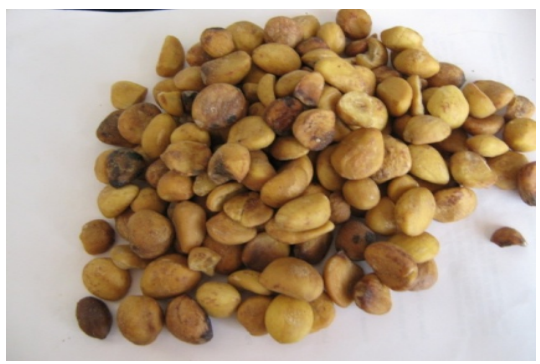

MFL Kernels

Figure 2. Morphology of Mesua ferrea L. (MFL) 
The acid value of the oil and biodiesel was measured as per AOCS official method Ca $5 \mathrm{a}-40$ as stated in Equation (1). The chemicals required for titration were freshly prepared caustic KOH $(0.25 \mathrm{~N})$ and phenolphthalein indicator ( $1 \%$ in $95 \%$ ethanol). The percentage of free fatty acids was calculated as oleic acid using Equation (1).

$$
\text { Free Fatty Acids of Oleic } \%=\frac{\text { ml of Alkali } \times N \times 56.1}{\text { wt of Sample }}
$$

The acidity (AD) of the crude MFL was $9.4 \%$ with an acid value (AV) $18.8 \mathrm{mg} \mathrm{KOH} / \mathrm{g}$. For transesterification reaction analytical grade methanol (purity 99.5\%, Loba Chemicals) and ethanol (99.9\%, Merck) were used without further treatment.

The chemicals required for iodine value estimation were purchased from Merck and prepared as follows: reagent grade iodine monochloride solution, potassium iodide solution $(15 \%)$, sodium thiosulphate $(0.1 \mathrm{~N})$, glacial acetic acid, chloroform and starch (1\%). The Iodine values of the oil and biodiesel were estimated as per AOCS official method Cd 1-25 using freshly prepared Wijs solution and starch indicator from the Equation (2).

$$
\text { The Iodine Value }=\frac{[(B-S) \times N \times 12.69]}{\text { Weight of Sample }}
$$

Where $\mathrm{B}=$ titration of blank; $\mathrm{S}=$ titration of sample; $\mathrm{N}=$ normality of sodium thiosulphate solution.

\subsection{Catalyst Preparation}

MBCUS was cut into thin pieces of the dimension $1.5 \mathrm{~cm} \times 15 \mathrm{~cm}$ and sun dried in March, 2011 for about 15 days, which were later burnt traditionally in an open environment upon a tin sheet for ash production. These ashes obtained were further processed in a furnace in the laboratory at $550{ }^{\circ} \mathrm{C}$ for one hour. For material balance, a piece of the fresh MBCUS was collected at sampling plastic bag of known weight and studied for proximate analysis. It was found that the fresh MBCUS contain $91.34 \%$ moisture at $105{ }^{\circ} \mathrm{C}, 7.45 \%$ volatile matter at $350{ }^{\circ} \mathrm{C}$ and $0.14 \%$ carbon at $550{ }^{\circ} \mathrm{C}$. While the ash obtained at $550{ }^{\circ} \mathrm{C}$ was $1.07 \%$ of the fresh MBCUS (Figure 3).

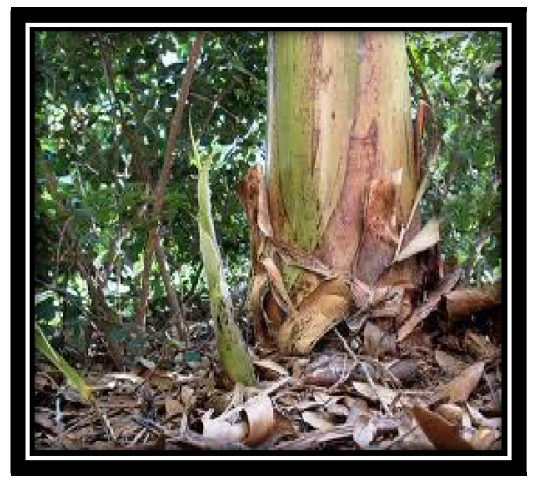

MBC trunk

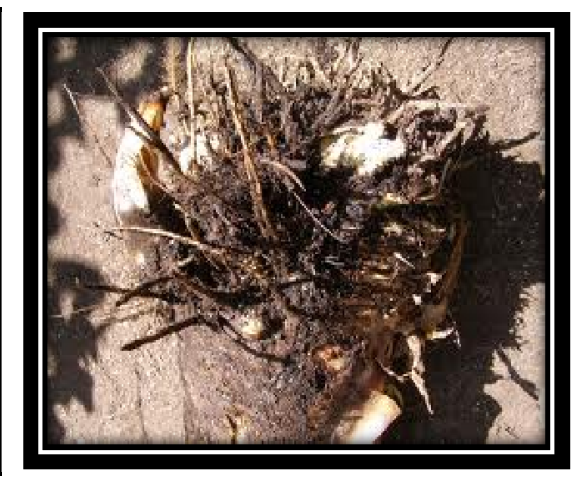

MBCUS Root

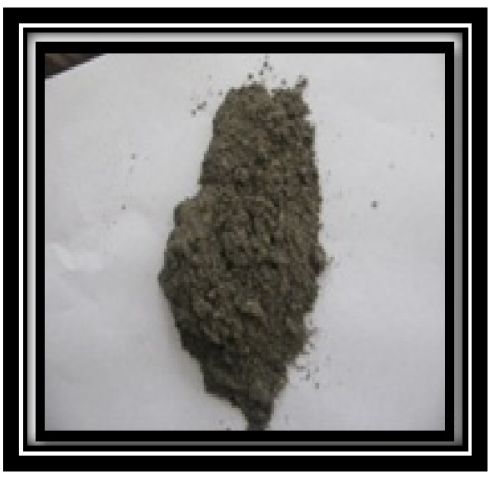

MBCUS Ash

Figure 3. Morphology of MBCUS catalyst

\subsection{Catalyst Characterization}

The physico-chemical characteristics of the MBCUS ash (Baked at $550{ }^{\circ} \mathrm{C}$ ) were analysed to estimate the catalytic activity and basic composition as per AOAC methods. The catalyst was analysed in a TGA instrument manufactured by Perkin Elmer, model STA 6000 for thermal and oxidative stability. The weight losses of the catalyst (prepared @ $550{ }^{\circ} \mathrm{C}$ ), temperature range $30-1000{ }^{\circ} \mathrm{C}$, heating rate $10{ }^{\circ} \mathrm{C} / \mathrm{min}$ and constant flow of air and nitrogen $(20 \pm 0.5 \mathrm{ml} / \mathrm{min})$ were recorded. The contents of the catalyst were ascertained from appropriate AOAC, TGA, XRF analysis and SEM EDX pattern. The basic strength of the catalysts (H-) was estimated using Hammett indicator method. The catalyst sample $(100 \mathrm{mg})$ was shaken along with suitable amount of Hammett indicators diluted with methanol and left to equilibrate for about two hours upto no colour change observed. The titrate color was then recorded. The following Hammett indicators were used: neutral red $\left(\mathrm{H}^{-}=6.8\right)$, bromothymol blue $\left(\mathrm{H}^{-}=7.2\right)$, phenolphthalein $\left(\mathrm{H}^{-}=9.3\right)$, 2,4-dinitroaniline $\left(\mathrm{H}^{-}=15.0\right)$, 4-nitroaniline $\left(\mathrm{H}^{-}=\right.$ 
18.4). The basic strength of the catalysts was defined as being stronger than the Hammett indicator if it showed a colour change but weaker if no colour changes observed.

The structural study of the catalyst was done with the XRD pattern using X-ray diffractometer (XRD). Nitrogen adsorption isotherms were obtained at $-196{ }^{\circ} \mathrm{C}$ using a Quantachrome NovaWin - Data Acquisition and Reduction (Quanta chrome Instrument) system. These isotherms were used to see the BET surface area, pore volume and pore size distribution.

The SEM images and subsequent EDX analysis of the samples were carried out using FE-SEM QUANTA 200 FEG of FEI Netherlands make. The EDX pattern showed the composition and different crystalline materials present in the MBCUS ash catalyst. The transmission electron microscope images of the MBCUS samples were taken using a Tecnai G2 20 of FEI Neitherlands make transmission electron microscope (TEM).

The nature, composition and detail physicochemical properties of the MBCUS nano-catalyst have been accepted for publication in a reputed journal recently (Sarma, Kumar, Aslam, \& Chouhan, 2014).

\subsection{Transesterification in Batch Reactor}

The tranesterification reactions were carried out in a HPHT Bench Top reactor of $1.8 \mathrm{~L}$ capacity (Amar equipments Company, Mumbai, India). The reactor contains to heating mantle, cooling system and pressure-temperature control and recording devices.

The average molecular weight was calculated from the triglyceride composition of MFL seed oil and was found to be 866 . The oil to alcohol molar ratio in the reaction mixture was kept at 1:9 and the catalyst concentration was kept at $1 \%, 3 \%$ and $5 \%$ of the initial oil mass. The reaction was carried out under $250{ }^{\circ} \mathrm{C}$ and $275{ }^{\circ} \mathrm{C}$ for easy conversion of the free fatty acids to ethyl ester and also for resisting, oxidation of the reactants. This was accomplished by stripping the reaction mixture inside the reactor. All the experiments were performed with a total oil, alcohol (ethanol) and catalyst volume not exceeding 1.5 L. The initial hydrogen pressure inside the reactor was maintained at $1.0 \times 10^{5} \mathrm{~Pa}$ (atmospheric) which rises up to $4.4 \times 10^{6} \mathrm{~Pa}$ with increasing internal vapour pressure (IP) at $275^{\circ} \mathrm{C}$. The reactions were also conducted in the absence of catalyst under the same set of experimental condition. In this instance, the internal vapour pressure raised up to $6.6 \times 10^{6} \mathrm{~Pa}$ at $275^{\circ} \mathrm{C}$. The mixture was vigorously stirred at 650 revolutions per minutes. Samples were removed by opening the flash bottom valve after completion of the reaction. The samples collected from the reactor were allowed to settle in a ventilator before analysis. Since triglycerides (TGs), diglycerides (DGs), monoglycerides (MGs) and free fatty acids (FFAs) analysis relates only with the oily liquid phase of the sample and the results are presented as percentage of the total oily mass, the oily mass was purged of impurities that might affect the final measurements. So, the oily phase was subsequently transferred to the rotary vacuum evaporator (Heydolph, Germany Make) and the unreacted alcohol was separated in $45-50{ }^{\circ} \mathrm{C}$ and $2.25 \times 10^{3} \mathrm{~Pa}$. Then, the samples were centrifuged to separate the catalyst, glycerine (GL) and oily phase. The upper layer of the centrifuged sample contained the oily phase (biodiesel), the lower one of the glycerine, while in the middle, between the oil and the glycerine phase appears the catalyst. The catalyst was later washed using petroleum ether and methanol to remove the bound ester and glycerol.

\subsection{Fuel Property Analysis of the FAEE}

The crude MFL seed oil was initially analyzed using GC FID detector as per AOCS Official method 1998, Ce 1-62 and Ce 2-26 at Punjab Biotechnology Incubator (Mohali) an NABL accredited laboratory of India. The fuel properties of the FAEE obtained at optimum conditions were analysed using appropriate ASTM D6751 and EN 14214 standard procedures specified for B100 biodiesel stocks.

\section{Results and Discussion}

\subsection{Structural Analysis and Porosity Analysis of MBCUS Catalyst}

The XRD analysis ascertains the presence of crystalline phases the in MBCUS catalyst, which have been reported earlier (Sarma, Kumar, Aslam, \& Chouhan, 2014). It has been found that the surface area of the catalyst is $38.710 \mathrm{~m}^{2} / \mathrm{g}$, total pore volume $4.233 \times 10^{-8} \mathrm{~m}^{3} / \mathrm{g}$ for pores smaller than $796.2 \times 10^{-11} \mathrm{~m}$ (Radius) at $\mathrm{P} / \mathrm{P}_{\mathrm{o}}$ equal to 0.98780 and pore size expressed as average pore radius is equal to $21.8681 \times 10^{-11} \mathrm{~m}$. These values are significantly better than earlier reported literature (Sharma, Khan, Puri, \& Tuli, 2012; Kumar et al., 2010). All these attributes show that the catalyst chosen could be an excellent one for transesterification reaction.

\subsection{SEM-EDX and TEM Analysis of MBCUS Catalyst}

The SEM-EDX analysis of the catalyst were conducted (Figure 4) and confirmed the presence of $\mathrm{C}\left(\mathrm{CaCO}_{3}\right), \mathrm{O}$ $\left(\mathrm{SiO}_{2}\right), \mathrm{Mg}(\mathrm{MgO}), \mathrm{Al}\left(\mathrm{Al}_{2} \mathrm{O}_{3}\right), \mathrm{Si}\left(\mathrm{SiO}_{2}\right), \mathrm{P}(\mathrm{GaP}), \mathrm{Cl}(\mathrm{KCl}), \mathrm{K}$ (MAD-10 Feldspar), CA (Wollastonite), as 
depicted in the Figure 4. The typical elemental composition as evaluated from Figure 4, that depicts the mass fraction composition as C (9.86\%), O (44.01\%), Mg (3.92\%), Al (1.21\%), Si (12.03\%), P (1.59\%), Cl (2.69\%), $\mathrm{K}(16.83 \%)$, Ca (7.19\%). Earlier studies of heterogeneously catalysed tranesterification reactions of vegetable oil have focused on single metal oxides, including $\mathrm{CaO}, \mathrm{MgO}, \mathrm{Al}_{2} \mathrm{O}_{3}$, zeolites, silicates etc.

Functionalized compounds such as calcium bentonite functionalised with potassium (Hoffmann \& Conradi, 1988), porous silica and pumice granules, mesoporous silica and metallosilicate materials of SBA-15 types (Sanz et al., 2012) were also shown very good activity during tranesterification as reported. Therefore, the versatile composition, including several alkali and alkaline earth metal oxides, carbonate and silica makes MBCUS ash a perfect heterogeneous catalyst for transesterification reaction (Sarma, Kumar, Aslam, \& Chouhan, 2014).
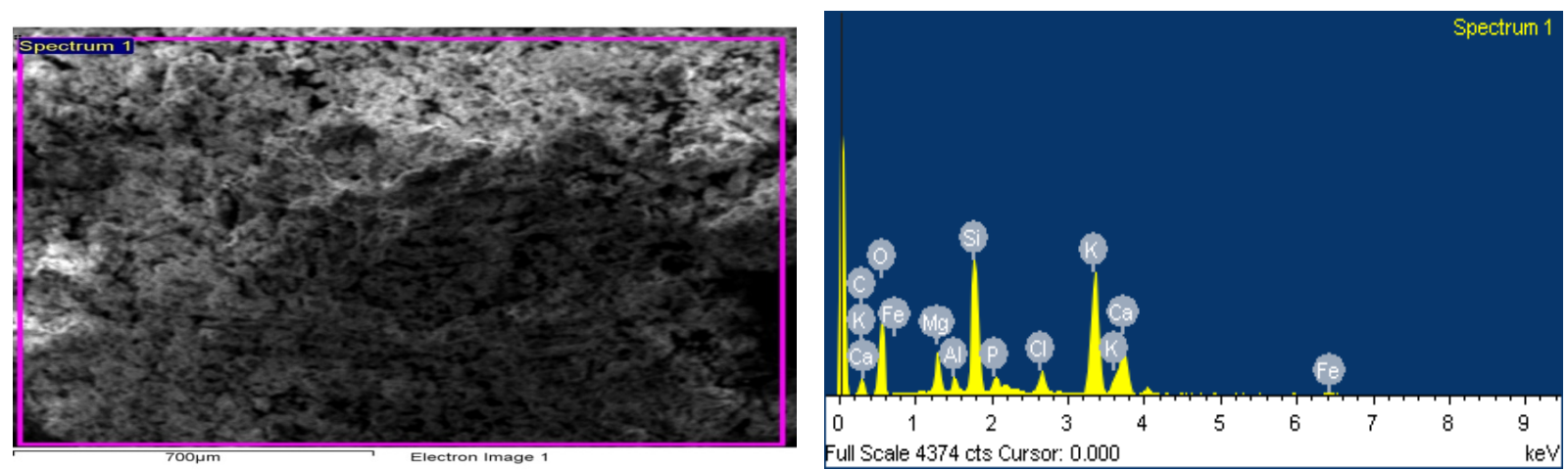

Figure 4. SEM-EDX spectrum and composition

The structural information of the catalyst was studied from the TEM images as shown in the Figure 5. It is clearly visible that the structural dimensions are similar (100 nm length) and brick like (Approx. $70 \mathrm{~nm} \times 20 \mathrm{~nm}$ $\times 15 \mathrm{~nm}$ ). The nano size structural dimension of MBCUS catalyst provided effective surfaces to their catalytic efficacy during tranesterification of triglyceride, irrespective of the free fatty acids present in the oil. Similar results were also covered by Boz, Degirmanbasi and Kalyon (2009) for the tranesterification of canola oil using nano- $\gamma-\mathrm{Al}_{2} \mathrm{O}_{3}$ loaded with $\mathrm{KF}$ that showed $97.7 \%$ ester yield with $3 \%$ catalyst loading.

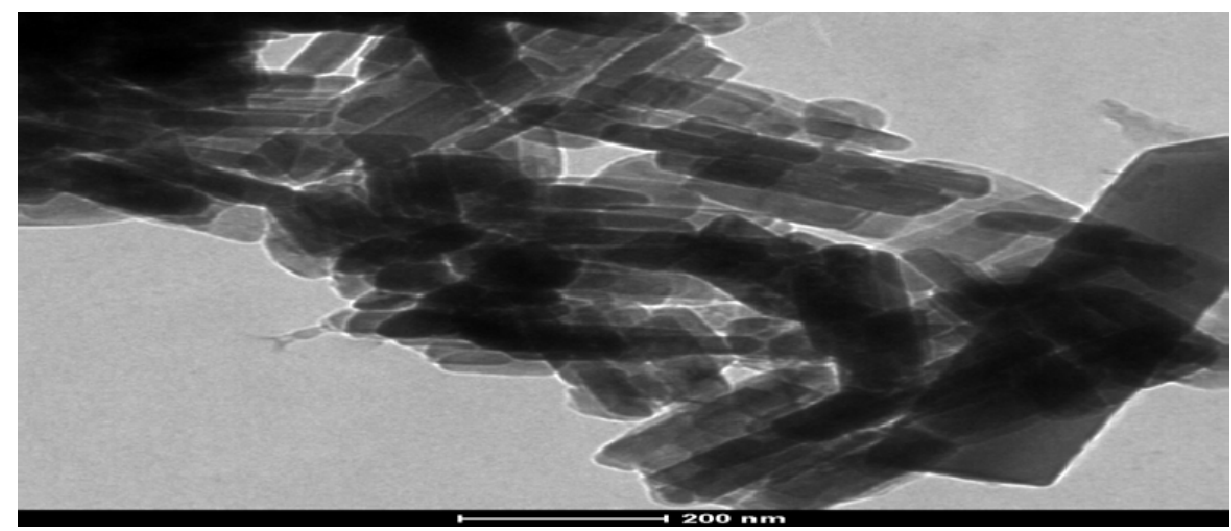

Figure 5. TEM images and structural information of MBCUS-catalyst

\subsection{Basicity Analysis of MBCUS Catalyst}

The basicity of the catalyst was determined within the range of $9.3<\mathrm{H}^{-}<15.0$. The base strength of MBCUS is thus stronger than the weakest indicator phenolphthalein $\left(\mathrm{H}^{-}=9.8\right)$ that exhibited a colour change from pink to colourless. However, it is weaker than the strongest indicator i.e. 2, 4-dinitroaniline $\left(\mathrm{H}^{-}=15.0\right)$ as no colour change was observed. 


\subsection{Metallic \& Non-Metallic Contents in MBCUS Catalyst}

Nonmetallic concentration in the MBCUS ash catalyst was found out using appropriate standard methods as applicable discussed in Table 2.

Table 2. Metallic \& non-metallic contents in MBCUS catalyst

\begin{tabular}{cccc}
\hline S. No. & Parameters & Concentration & Specification \\
\hline 1 & Chloride & $0.60 \mathrm{wt} . \%$ & \multirow{2}{*}{ AOAC 915.01} \\
2 & Carbonate & ND( MDL: $2 \mathrm{mg} / \mathrm{kg})$ & \\
3 & Sodium & $0.34 \mathrm{wt} . \%$ & \\
4 & Potassium & $27.70 \mathrm{wt} . \%$ & AOAC 975.03 \\
5 & Lead & $5.19 \mathrm{mg} / \mathrm{kg}$ & \\
6 & Cobalt & $1.97 \mathrm{mg} / \mathrm{kg}$ & TGA method \\
7 & Carbon & $4.5 \mathrm{wt} . \%$ & \\
8 & Silica & $37.00 \mathrm{wt} . \%$ & \\
\hline
\end{tabular}

\subsection{Product Analysis by GC}

Important Physico-Chemical Characteristics of MFL seed oil have been represented in Table 3. The process for the production was optimized with regard to the conversion of the oil to ester @ $250{ }^{\circ} \mathrm{C}$ and @ $275{ }^{\circ} \mathrm{C}$. The biodiesel was produced from MFL seed oil under the specified experimental condition and found in conformity to ASTM standards with regard to fuel property while the reaction was carried out at $275{ }^{\circ} \mathrm{C}$. It has been observed that the acid value of MFL oil was $18.8 \mathrm{mg} \mathrm{KOH} / \mathrm{g}$ oil (which is equivalent to about $9.4 \mathrm{wt} . \% \mathrm{FFA}$ content), the acid value of the end product was $1.6 \mathrm{mg} \mathrm{KOH} / \mathrm{g}$ oil (Figure 6). This has been observed even without externally applied hydrogen pressure. The experiment was repeated further for MFL oil at $275{ }^{\circ} \mathrm{C}$ without $\mathrm{H}_{2}$ pressure. The tranesterification reaction was carried out under $250{ }^{\circ} \mathrm{C}$ and $275^{\circ} \mathrm{C}$ for the conversion of FFAs and triglycerides to fatty acid ethyl-ester. This was accomplished by stripping the reaction mixture inside the reactor. All the experiments were performed with a total oil, alcohol (ethanol) and catalyst volume not exceeding $1.5 \mathrm{~L}$. The initial hydrogen pressure inside the reactor was maintained at $1.0 \times 10^{5} \mathrm{~Pa}$ (atmospheric) which raises up to $4.4 \times 10^{6} \mathrm{~Pa}$ during the reaction along with increasing internal vapour pressure (IP) at $275{ }^{\circ} \mathrm{C}$ due to the presence of ethanol. The reactions were also conducted in the absence of catalyst under the same set of experimental condition. In this instance, the internal vapour pressure raised up to $6.6 \times 10^{6} \mathrm{~Pa}$ at $275^{\circ} \mathrm{C}$. This clearly demonstrated that the presence of hydrogen does not affect tranesterification.

Table 3. Physico-chemical characteristics of Mesua ferrea L. seed oil

\begin{tabular}{lcc}
\hline Parameters & MFL Oil & MFL-FAEE (B100) \\
\hline Density at $40{ }^{\circ} \mathrm{C}\left(\mathrm{g} / \mathrm{cm}^{3}\right)$ & 0.90059 & 0.873 \\
Specific gravity at $20{ }^{\circ} \mathrm{C}\left(\mathrm{g} / \mathrm{cm}^{3}\right)$ & 0.90762 & 0.879 \\
API density at $15{ }^{\circ} \mathrm{C}\left(\mathrm{g} / \mathrm{cm}^{3}\right)$ & 0.91735 & 0.890 \\
Distillation @ $360{ }^{\circ} \mathrm{C}(\mathrm{wt} \%)$ & -- & 90 \\
Flash point $\left({ }^{\circ} \mathrm{C}\right)$ & 115.0 & 113 \\
Calorific value $\left(\mathrm{MJ} \mathrm{kg}{ }^{-1}\right)$ & 36.0 & 35 \\
Viscosity @ $40{ }^{\circ} \mathrm{C}(\mathrm{cSt})$ & 34.10 & 5.525 \\
Acid Value $(\mathrm{mg} \mathrm{KOH} / \mathrm{g})$ & 18.8 & 1.8 \\
Free fatty acids $(\%)$ as oleic & 9.40 & 0.8 \\
Iodine Value $(\mathrm{g} \mathrm{I} / 100 \mathrm{~g})$ & 131.31 & 113.24 \\
Rams bottom carbon residue $(\mathrm{wt} \%)$ & 0.99 & 0.250 \\
Copper strip corrosion & $1 \mathrm{a}$ & $1 \mathrm{a}$ \\
\hline
\end{tabular}


The iodine value decreases with increasing the catalysts percentage with respect to biodiesel production. It was observed that the unsaturation in the biodiesel decreased as iodine values decreased from 130 to 112 as shown in Figure 7. Iodine number basically represents the degree of unsaturation, the larger is the number higher is the unsaturation. While tranesterification took place some of the unsaturation present in the fatty acid chain got saturated with the proton shift that takes place in situ. This also indirectly indicated the conversion of oil to FAEE.

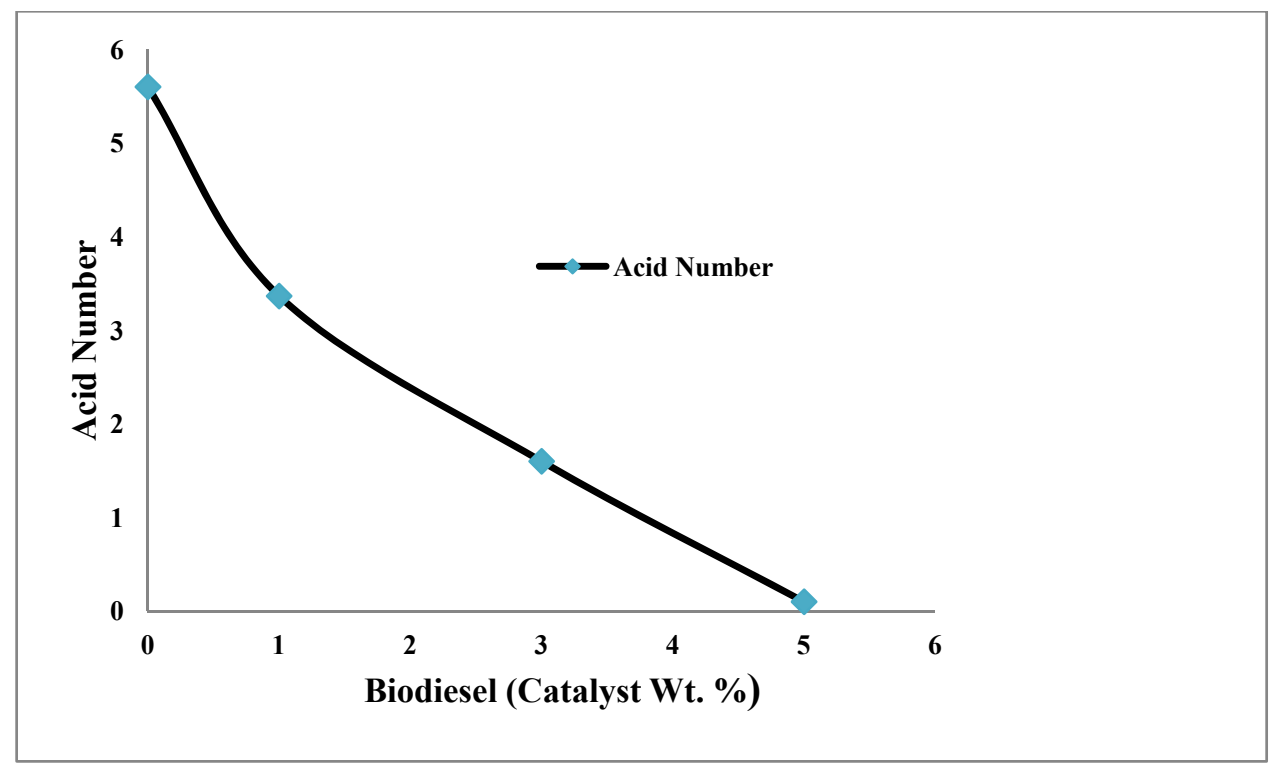

Figure 6. FFA trend using MBCUS

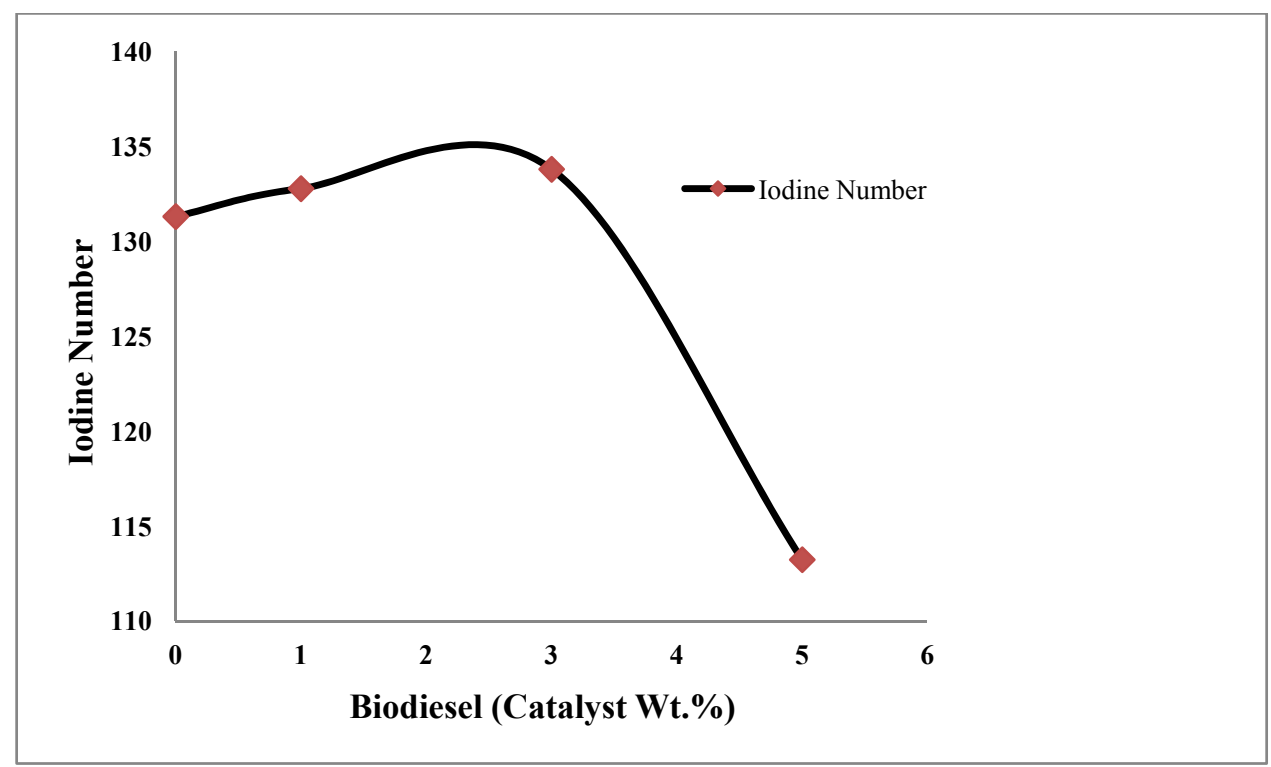

Figure 7. Iodine index variation MF oil to FAEE

It has been observed that the FFA level drastically decreased to near about $1.8 \mathrm{mg} \mathrm{KOH} / \mathrm{g}$ from $18.8 \mathrm{mg} \mathrm{KOH} / \mathrm{g}$ oil in $1 \mathrm{~h}$. This clearly demonstrated the evidence of efficacy of the catalysts and furthers no effect of hydrogen pressure upon FFA conversion at higher temperature. MBCUS is a very good catalyst due to high reactivity and efficacy during the transesterification and the negligible cost of production. The catalyst and product separation were much easier as compared to other available methods (two step transesterification). MBCUS catalysts can be commercialized for the bio-diesel production for the development of society and economic growth of the Country as well. 
The TGA profile of the FAEE was conducted under a constant flow of $\mathrm{N}_{2} 20 \mathrm{ml} / \mathrm{min}$ in $1 \mathrm{~h}$ constant heating rate and observed that over $90 \%$ of the FAEE was boiled off at $350{ }^{\circ} \mathrm{C}$ confirming the conversion of MFL to FAEE (Figure 8). The GC profile of the FAEE of MFL was recorded and found that $95 \%$ of the oil was converted to FAEE at $275^{\circ} \mathrm{C}$ and one hour reaction time in a batch process in 1:9 molar ratio of oil: alcohol as specified in Figure 9 in the absence of $\mathrm{H}_{2}$ pressure. The same was also confirmed from the vacuum distillation of the FAEE obtained and $90 \%$ recovery was found at $360{ }^{\circ} \mathrm{C}$ as per ASTM D 6751-07 b. The distillation characteristics are regarded as the most important parameter of any liquid fuel, which represents volatility during combustion and formation of proper air-fuel mixture. Both the Gas chromatograph profile and distillation characteristics, are therefore in accordance with the specified standards of the FAEE and can be regarded as a very safe fuel for our purpose.

The MBCUS nano - catalyst could be reused for three times with the reduction of conversion efficacy of oil to FAEE by about $20 \%$, which was reported in our previous publication during tranesterification of Jatropha oil to FAME (Sarma, Kumar, Aslam, \& Chouhan, 2014).

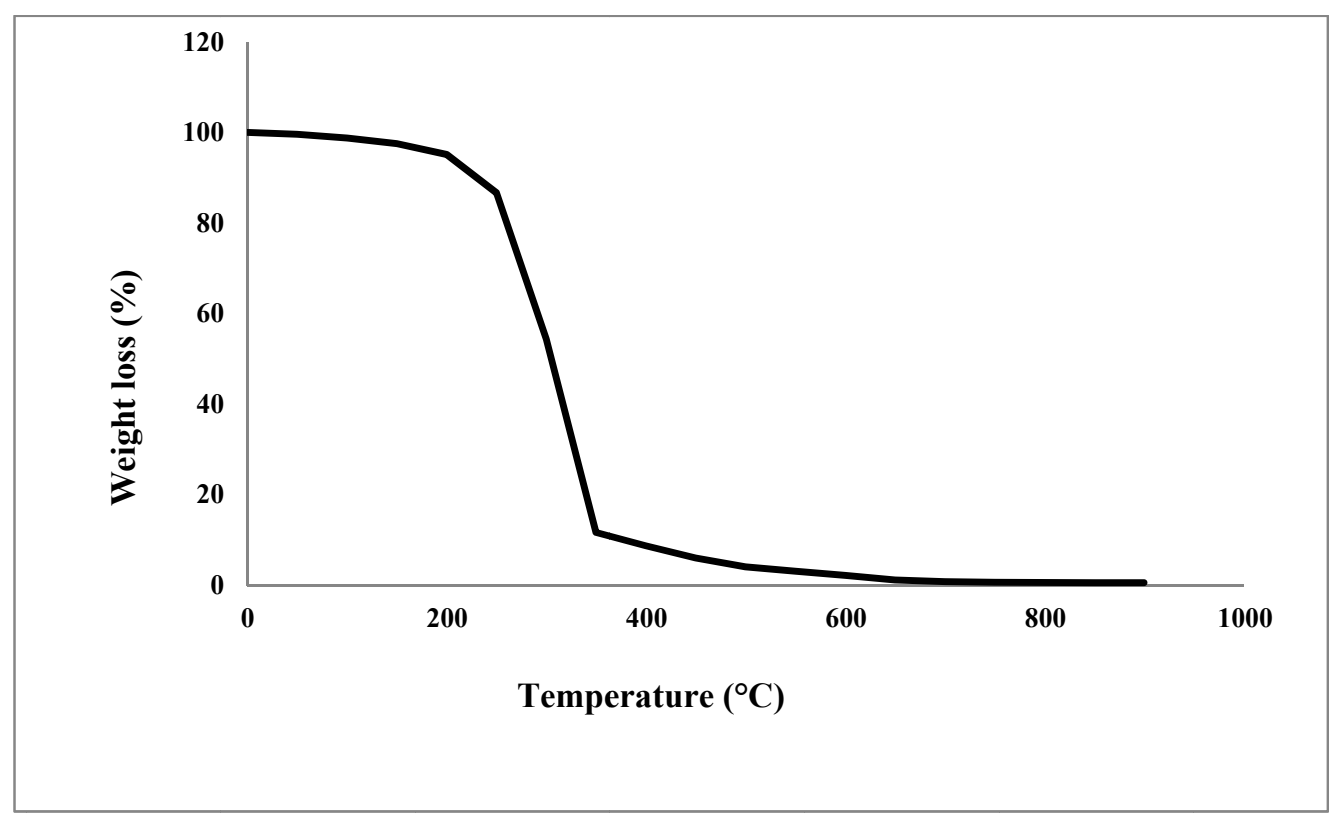

Figure 8. TGA profile of the MF FAEE obtained

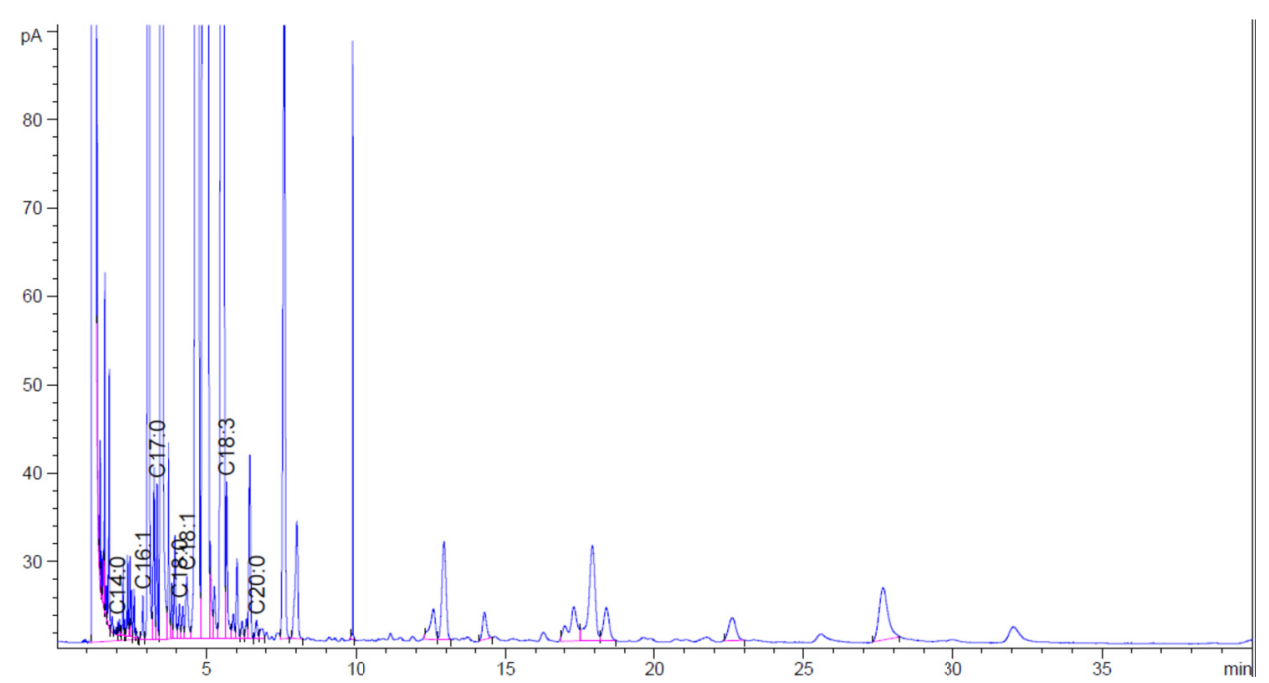

Figure 9. GC Profile of the MF FAEE obtained 


\section{Conclusion}

High free fatty acid containing MFL seed oil could be transesterified with ethanol (1:9 M ratio) in a single batch process using $5 \mathrm{wt} . \%$ MBCUS and 1 with or without external pressure in closed reactors. The vapour pressure inside the reactor increased upto $3.8 \mathrm{MPa}$ even without external pressure. The experiment was not conducted beyond $300{ }^{\circ} \mathrm{C}$ because at that stage poly unsaturated fatty acids would have been cracked when the reaction time exceeds $15 \mathrm{~min}$. The MBCUS nano-catalyst performed well during the transesterification reaction with good reactivity and reusability. This technology is applicable to most types of oil having high percentage of free fatty acids. The industrialist may take an interest in using such materials while setting up biodiesel production, refinery in the near future for all types of high free fatty acid containing oil.

\section{Acknowledgements}

Finally, the authors acknowledge the Ministry of New and Renewable Energy, Govt of India, New Delhi for financial assistance in the form of project grants 7/152/2010-BF date 13/09/2011 for carrying out the research and APCSEET2013 for funding the travel grants during the presentation and covering the publication fees.

\section{References}

Adebayo, G. B., Ameen, O. M., \& Abass, L. T. (2011). Physico-chemical properties of biodiesel produced from Jatropha Curcas oil and fossil diesel. Journal of Microbiology and Biotechnology Research, 1(1), 12-16.

Boz, N., Degirmenbasi, N., \& Kalyon, D. M. (2009). Conversion of biomass to fuel: Transesterification of vegetable oil to biodiesel using $\mathrm{KF}$ loaded nano- $\gamma-\mathrm{Al}_{2} \mathrm{O}_{3}$ as catalyst. Applied Catalysis B: Environmental, 89(3), 590-596. http://dx.doi.org/10.1016/j.apcatb.2009.01.026

Dennis, T. J., Kumar, K. A., \& Srimannarayana, G. (1988). A new cyclo hexadione from Mesua ferrea. Phytochemistry, 27(7), 2325-2327. http://dx.doi.org/10.1016/0031-9422(88)80153-5

Dorado, M. P., Ballesteros, E., López, F. J., \& Mittelbach, M. (2004). Optimization of alkali-catalyzed transesterification of Brassica C arinata oil for biodiesel production. Energy \& Fuels, 18(1), 77-83. http://dx.doi.org/10.1021/ef0340110

Ebiura, T., Echizen, T., Ishikawa, A., Murai, K., \& Baba, T. (2005). Selective transesterification of triolein with methanol to methyl oleate and glycerol using alumina loaded with alkali metal salt as a solid-base catalyst. Applied Catalysis A: General, 283(1), 111-116. http://dx.doi.org/10.1016/j.apcata.2004.12.041

Gaurav, D., Siddharth, J., \& Mahendra Pal, S. (2011). Pongamia as a Source of Biodiesel in India. Smart Grid and Renewable Energy, 2011.

Gryglewicz, S. (1999). Rapeseed oil methyl esters preparation using héterogeneous catalysts. Bioresource Technology, 70(3), 249-253. http://dx.doi.org/10.1016/S0960-8524(99)00042-5

Hoffmann, M. M., \& Conradi, M. S. (1998). Hydrogen exchange reactions in supercritical media monitored by in situ NMR. The Journal of Supercritical Fluids, 14(1), 31-40. http://dx.doi.org/10.1016/S0896-8446(98)00094-1

Kim, H. J., Kang, B. S., Kim, M. J., Park, Y. M., Kim, D. K., Lee, J. S., \& Lee, K. Y. (2004). Transesterification of vegetable oil to biodiesel using heterogeneous base catalyst. Catalysis Today, 93, 315-320. http://dx.doi.org/10.1016/j.cattod.2004.06.007

Kumar, S., Pulikottil, A. C., Sharma, A., Sarkar, M., Kagdiyal, V., Yadav, A., ... Kumar, A. (2010). A catalyst composition for transesterification of organically/naturally derived oils and fats to produce alkyl esters and process for preparing the same. WO, 20998, A2.

López-Sanz, J., Pérez-Mayoral, E., Soriano, E., Sturm, M., Martín-Aranda, R. M., López-Peinado, A. J., \& Čejka, J. (2012). New inorganic-organic hybrid materials based on SBA-15 molecular sieves involved in the quinolines synthesis. Catalysis Today, 187(1), 97-103. http://dx.doi.org/10.1016/j.cattod.2011.12.015

Lukić, I., Krstić, J., Jovanović, D., \& Skala, D. (2009). Alumina/silica supported $\mathrm{K}_{2} \mathrm{CO}_{3}$ as a catalyst for biodiesel synthesis from sunflower oil. Bioresource technology, 100(20), 4690-4696. http://dx.doi.org/10.1016/j.biortech.2009.04.057

Sarma, A. K., Konwer, D., \& Bordoloi, P. K. (2005). A comprehensive analysis of fuel properties of biodiesel from Koroch seed oil. Energy \& Fuels, 19(2), 656-657. http://dx.doi.org/10.1021/ef049754f 
Sarma, A. K., Kumar, P., Aslam, M., \& Chouhan, A. P. S. Preparation and Characterization of Musa balbisiana Colla Underground Stem Nano-material for Biodiesel Production Under Elevated Conditions. Catalysis Letters, 1-10.

Sharma, M., Khan, A. A., Puri, S. K., \& Tuli, D. K. (2012). Wood ash as a potential heterogeneous catalyst for biodiesel synthesis. Biomass and Bioenergy, 41, 94-106. http://dx.doi.org/10.1016/j.biombioe.2012.02.017

Tanabe, K., \& Hölderich, W. F. (1999). Industrial application of solid acid-base catalysts. Applied Catalysis A: General, 181(2), 399-434. http://dx.doi.org/10.1016/S0926-860X(98)00397-4

Vicente, G., Martınez, M., \& Aracil, J. (2004). Integrated biodiesel production: a comparison of different homogeneous catalysts systems. Bioresource Technology, 92(3), 297-305. http://dx.doi.org/10.1016/j.biortech.2003.08.014

Zhou, W., Konar, S. K., \& Boocock, D. G. (2003). Ethyl esters from the single-phase base-catalyzed ethanolysis of vegetable oils. Journal of the American Oil Chemists' Society, 80(4), 367-371. http://dx.doi.org/10.1007/s11746-003-0705-1

\section{Copyrights}

Copyright for this article is retained by the author(s), with first publication rights granted to the journal.

This is an open-access article distributed under the terms and conditions of the Creative Commons Attribution license (http://creativecommons.org/licenses/by/3.0/). 